\title{
OPTIMASI POLA TANAM DAN ALOKASI INPUT UNTUK PENINGKATAN KETAHANAN PANGAN RUMAH TANGGA DI \\ LAHAN PASANG SURUT KABUPATEN KUBU RAYA KALIMANTAN BARAT
}

\author{
(CROPPING PATTERN OPTIMALISATION AND INPUT \\ ALLOCATION FOR IMPROVING HOUSEHOLD FOOD SECURITY IN \\ SWAMP LAND DISTRICT OF KUBU RAYA WEST KALIMANTAN)
}

Akhmad Musyafak 1), Irham 2), Slamet Hartono 2), dan Jamhari 2)

1) Peneliti BPTP Kalimantan Barat,

2) Dosen Fakultas Pertanian UGM 2)

\begin{abstract}
The research was conducted in the district of Kubu Raya which is focused on swamp land. The purpose of this study are (a) optimizing the allocation of cropping pattern and input to achieve household food security and income maximum, (b) to simulate changes in input prices and output and its impact on cropping patterns, household income, and allocation of inputs. Location selected by purposive sampling technique taking into account the typology of land and type of overflow, whereas the primary data collected from farm households by simple random sampling technique. Data were analyzed with linear programming and sensitivity analysis. An important result of this study are as follows: (1) Optimal cropping patterns in swamp lands are as follows: (a) the type of $S M A$ / A, paddy field: rice - rice, (b) the type of SMP / A, paddy field: rice - rice, and dry land: coconut, (c) type SMP / B, paddy fields: corn-corn, and dry land: fruit, (d) the type of SMP / C, paddy field: rice-paddy and dry land: coconut, (e) type bergambut / B, wetland : paddy-rice, and dry Ahan: coconut, (f) type bergambut / C, paddy field: ricepaddy and dry land: coconut, $(g)$ the type of peat is / B, the paddy field: rice-paddy, (h) the type of shallow peat / $D$, wet land: paddy-rice, and dry land: rubber; (2) the optimal allocation of inputs consisting of family labor 166.74 day of man work/year, rent labor 132.74 day of man work/year, seed of paddy $70.54 \mathrm{~kg} /$ year, Urea $189.28 \mathrm{~kg} /$ year, SP36 $94.34 \mathrm{~kg} /$ year, $\mathrm{KCl} 56.35 \mathrm{~kg} /$ year, NPK $75.66 \mathrm{~kg} /$ year, organic fertilizer $65.99 \mathrm{~kg} /$ year, herbicide $8.62 \mathrm{lt} /$ year, dan pesticida $2.29 \mathrm{lt} /$ year; (3) the actual household income of Rp 2,200,000.00 / household / year, if carried out optimization of unconditional "food patterns of national expectations/FPNE" increased to $R p$ 3,883,234.87 / household / year and if there is a requirement of the FPNE decreased to $R p$ 1,285,839.37 / household / year. (4) the price of rice and corn prices are most sensitive to fluctuations. If the price of rice rose more than $5 \%$ or the price of corn rose more than $50 \%$ (cateris paribus) the optimal solution will change. Likewise, if the price of rice fell by more than $34 \%$ or corn prices fell more than 9\% (cateris paribus) the optimal solution will change. (5) The simulation results show that the rise in input prices and output prices $10 \%$ did not alter the optimal solution. But the impact on household income increased by $37.87 \%$
\end{abstract}


(unconditional FPNE), and $114.37 \%$ (provided FPNE). Simulated 10\% decrease in output price and input prices fixed, it does not alter the optimal solution, but the impact on the decline in household income by 152.15\% (unconditional FPNE) and 459.49\% (provided FPNE).

Keywords: optimize, farm household, swamp area, food security,

\section{PENDAHULUAN}

Wilayah Kalimantan Barat seluas 14,680.700 hektar, yang terdiri dari lahan kering 3.012.814 hektar (20,49\%); lahan pasang surut (rawa) seluas 1.904 .100 hektar $(12,95 \%)$, gambut 1.677 .550 hektar $(11,41 \%)$, lahan non pasang surut 18.750 hektar $(0,13 \%)$ Lahan perairan seluas 8.273 hektar dan lainnya adalah lahan pegunungan (BPS Kalbar, 2006).

Luas lahan pasang surut di Kalimantan Barat adalah 1.904.100 ha atau $12,95 \%$ dari total luas wilayah $(14,680.700$ ha). Lahan pasang surut merupakan lahan marginal yang dicirikan adanya permasalahan keracunan pirit, interusi air laut, salinitas, sehingga produktifitasnya rendah. Hal ini akan mempengaruhi ketersediaan pangan rumah tangga tani. Kondisi infrastruktur yang terbatas, akses pemasaran yang terbatas, fluktuasi harga akan berpengaruh pada akses pangan. Resultante dari semua itu bermuara pada ketahanan pangan rumah tangga tani.

Sektor pangan merupakan sektor penentu tingkat kesejahteraan sebagian besar penduduk di perdesaan yang terdiri dari petani berlahan sempit dan buruh tani yang sebagian besar adalah rakyat miskin. Tidak kalah pentingnya pangan juga menentukan kesejahteraan konsumen miskin perkotaan yang sebagian besar porsi pendapatannya digunakan untuk konsumsi (Welirang, 2007). Selain itu, menurut Pakpahan (2008) ketahanan pangan mempunyai peran strategis dalam memenuhi salah satu hak azasi manusia; membangun kualitas sumber daya manusia; dan membangun pilar bagi ketahanan nasional.

Sedangkan definisi ketahanan pangan yang diformulasikan oleh Pemerintah RI adalah seperti yang tertuang dalam UU No. 7 Tahun 1996 tentang Pangan yaitu kondisi terpenuhinya pangan bagi setiap rumah tangga yang tercermin dari tersedianya pangan yang cukup, baik jumlah maupun mutunya, aman, merata, dan terjangkau (Suryana, 2008).

Subtansi dari definisi ketahanan pangan tersebut adalah setiap rumah tangga/individu terpenuhi kebutuhan pangannya (a) secara cukup, (b) setiap saat, (c) aman, (d) merata, (e) sesuai selera, (f) terjangkau, (g) untuk hidup sehat dan produktif.

Ada dua sisi penting dalam upaya ketahanan pangan, yaitu (1) bagaimana dapat memenuhi kebutuhan pangan yang bergizi, beragam dan berimbang dengan harga yang terjangkau oleh rakyatnya; dan (2) bagaimana dapat memberikan iklim yang kondusif dan insentif yang baik bagi para produsen 
pangan (khususnya para petani, peternak dan nelayannya) agar dapat meningkatkan produksi dan produktivitasnya (Pambudy, 2006).

Beberapa peneliti mengungkapkan adanya berbagai masalah pada komponen ketahanan pangan rumah tangga, terutama ketersediaan dan distribusi pangan, daya beli, serta sosial budaya, khususnya pada penerapan pengetahuan gizi rumah tangga, yang sangat dipen garuhi oleh kebiasaan makan setempat (Hasan, 1995; Khomsan, 1996; Mangkuprawira, 1996; Soetrisno, 1996; Susanto, 1996). Perasamasalahan tersebut akhirnya berpengaruh buruk pada diversifikasi pangan yang menentukan konsumsi pangan dan status gizi rumah tangga terutama pada kelompok masyarakat berpendapatan rendah, serta semakn menunda tercapainya pola pangan harapan (PPH) nasional (Elfindri dan Dasvarma, 1996; Suhardjo, 1994; Soetrisno, 1995, 1996).

Seringkali rumah tangga tani mempunyai kemampuan yang rendah dalam menanggulangi krisis pangan dan pendapatan (Monteverde, 1987; Pabinru, et al, 1993; Pakpahan, 1993). Adanya krisis pangan yang mengikuti krisis ekonomi 1997 semakin mengedepankan pentingnya ketahanan pangan rumah tangga.

Kondisi rendahnya ketahanan pangan rumah tangga dapat diperberat dengan kondisis sumberdaya pertanian yang marginal lahan pasang surut. Rendahnya status gizi rumah tangga tani yang disebabkan oleh rendahnya jumlah dan mutu konsumsi pangan serta kurang lestarinya usahatani di lahan pasang surut, merupakan kendala bagi rumah tangga tani dalam memenuhi persyaratan ketahanan pangan rumah tangga.

Apabila produksi pangan rumah tangga yang berasal dari usahatani yang berkelenjutan tidak mampu memenuhi persyaratan konsumsi pangan sesuai pola pangan harapan $(\mathrm{PPH})$ nasional, maka kekurangan konsumsi pangan tersebut dipenuhi dengan membeli bahan pangan di pasar.

Daya beli rumah tangga tani terhadap bahan pangan ditentukan oleh dua hal, yaitu (1) pendapatan rumah tangga berupa kas masuk (cash supply) yang berasal dari seluruh sumber kas rumah tangga, dan (2) harga bahan pangan yang dibeli. Pada tingkat harga makanan yang tetap, daya beli rumah tangga terhadap pangan dapat ditingkatkan dengan memperbaiki pendapatan rumah tangga.

Untuk lebih memahami secara mendalam dan merumuskan kebijakan yang tepat tentang ketahanan pangan rumah tangga tani di agroekologi pasang surut di Kalimantan Barat, maka perlu dilakukan penelitian ini. Hasil penelitian ini diharapkan dapat dimanfaatkan oleh stake holders dan beneficiaries di tingkat pusat, propinsi, maupun kabupaten dalan menangani ketahanan pangan rumah tangga tani di agroekologi pasang surut Kalimantan Barat atau kemungkinan replikasi di tempat lain.

Berdasarkan latar belakang yang telah diuraiakan sebelumnya dapat dirumuskan tujuan penelitian sebagai berikut: (a) Melakukan optimasi pola tanam dan alokasi input pertanian dalam rangka memenuhi pola pangan harapan $(\mathrm{PPH})$ nasional rumah tangga tani sekaligus memaksimumkan pendapatan (net cash flow) rumah tangga tani, dan (b) Menganalisis simulasi dampak perubahan 
harga input, dan harga output terhadap pola tanam, pendapatan, dan alokasi sumberdaya pertanian

\section{METODOLOGI}

\section{Pendekatan}

Pada penelitian ini menggunakan metode dasar deskriptif analisis. Penelitian deskriptif bertujuan untuk membuat gambaran situasi atau kejadian atau memberikan gambaran hubungan antara fenomena, menguji hipotesis, membuat prediksi serta implikasi dari suatu masalah yang ingin dipecahkan (Nasir, 1988).

Pengumpulan data menggunakan metode survey yaitu cara pengumpulan data dengan pengamatan atau penyelidikan yang kritis untuk mendapatkan keterangan terhadap suatu persoalan tertentu dan di dalam suatu daerah tertentu (Teken, 1965). Kajian ini berdasarkan alasan riset termasuk riset terpakai (applied research), menurut tempat penelitian termasuk riset lapangan (field research), berdasarkan teknik riset menggunakan teknik survey (survey technique). Penelitian teknik survey adalah penelitian bersifat diskriptif untuk menguraikan keadaan tanpa melakukan perubahan variabel tertentu (Supranto, 1997).

\section{Lokasi dan Waktu Penelitian}

Penelitian ini dilakukan di : Kabupaten Kubu Raya Propinsi Kalimantan Barat yang difokuskan di agroekologi pasang surut yang merupakan eks-ISDP (Integrated Swamps Development Project) tahun 1995 sampai tahun 2000. Adapun waktu penelitian dilakukan mulai Januari sampai Desember 2010.

\section{Jumlah Sampel dan Teknik Pengambilan Sampel}

Pemilihan lokasi menggunakan teknik purpossive sampling. Menurut Pasaribu (1983); Suratno dan Arsyad (1999), pengertian purposive sampling adalah memilih sampel secara sengaja dengan pertimbangan-pertimbangan khusus yang dimiliki sample tersebut. Pertimbangan khusus yang digunakan dalam memilih sampel adalah (1) tipe luapan yang meliputi Tipe A, Tipe B, Tipe C, dan Tipe D, (2) tipologi lahan yang meliputi alluvial, sulfat masam aktual, sulfat masam potensial, dan gambut. Sedangkan Teknik pengambilan sampel petani menggunakan simple random sampling, dimana jumlah sampel dalam penelitian ini adalah 75 rumah tangga tani.

\section{Teknik Pengambilan Data}

Jenis data yang akan dikumpulkan dalam pengkajian ini adalah data primer dan data sekunder. Data primer diperoleh dari sumbernya secara langsung yaitu petani. Sedangkan data sekunder diperoleh dari berbagai instansi yang terkait seperti BPS Kalimantan Barat, Dinas Pertanian 
kabupaten/propinsi, Badan Ketahanan Pangan kabupaten/propinsi, Bappeda, dan lain-lain.

Teknik pengumpulan data dilakukan dengan teknik observasi, dan teknik wawancara. Teknik oberservasi yaitu cara pengumpulan data dengan pengamatan langsung secara cermat dan sistematik baik secara partisipatif maupun non partisipatif. Teknik wawancara yaitu cara pengumpulan data dengan bertanya langsung atau berdialog dengan responden. Proses wawancara menggunakan daftar pertanyaan terstruktur / kuosioner (Suratno dan Arsyad, 1999).

\section{Metode Analisis}

Untuk menentukan pola tanam yang optimal, tingkat penggunaan input optimal, dan pendapatan maksimal digunakan analisis Linier Programming, yaitu teknik matematis yang digunakna untuk menganalisis alokasi sumberdaya terbatas antara aktifitas yang bersaing untuk memaksimumkan nilai fungsi tujuan (Heady dan Candler, 1973). Secara umum dalam linier programming terdiri atas fungsi tujuan dan kendala yang dapat dirumuskan sebagai berikut:

Memaksimumkan:

$$
Z=C_{1} X_{1}+\ldots+C j X j+\ldots+C_{n} X_{n}
$$

dengan kendala:

$$
\begin{aligned}
& a_{11} X_{1}+\ldots+a_{1 j} X_{j}+\ldots+a_{1 n} X_{n} \leq b_{1} \\
& a_{i 1} X_{1}+\ldots+a_{i j} X_{j}+\ldots+a_{i n} X_{n} \leq b_{i} \\
& a_{m 1} X_{1}+\ldots+a_{m j} X_{j}+\ldots+a_{m n} X_{n} \leq b_{m} \\
& a_{\mathrm{f} 1} X_{1}+\ldots+a_{f j} X_{j}+\ldots+a_{f n} X_{n}=\text { PPH nasional dan } X_{j} \geq 0
\end{aligned}
$$

Keterangan:

$\mathrm{Z} \quad$ = fungsi tujuan (memaksimumkan aliran kas bersih/net cash flow)

$X_{j}=$ alternatif aktifitas dalam produksi, konsumsi, pemasaran, dan keuangan

cj $\quad=$ penambahan $(\geq 0)$ atau pengurangan $(\leq 0)$ dari $Z$ oleh suatu unit $X_{j}$

$\mathrm{b}_{\mathrm{j}} \quad=$ kendala berupa persayaratan $(\geq)$; pembatas $(\leq)$; persamaan $(=)$;

$a_{i j} \quad=$ penambahan $(\leq 0)$ atau pengurangan $(\geq 0)$ dari $b_{i}$ oleh suatu unit $X_{j}$

$\mathrm{a}_{\mathrm{f} 1} \quad=$ tingkat dimana persyaratan ketahanan pangan rumah tangga menurun $(\geq 0)$ atau meningkat $(\leq 0)$ oleh pilihan-pilihan produksi, konsumsi, pemasaran, dan keuangan

$\mathrm{a}_{\mathrm{uj}} \quad=$ tingkat dimana uang tunai kas menurun $(\geq 0)$ atau meningkat $(\leq 0)$ oleh pilihan-pilihan produksi, konsumsi, pemasaran, dan keuangan 
Model rumah tangga tani yang dikembangkan adalah model programasi linier rumah tangga tani yang mempertimbangkan persyaratan ketahanan pangan. Parameter model ditetapkan berdasarkan data rumah tangga tani, selanjutnya perubahan ketahanan pangan disimulasikan dalam model yang valid.

Aktifitas-aktiftas dalam model ini dibedakan kedalam empat kelompok, yaitu produksi, konsumsi, pemasaran, dan keuangan. Secara lebih rinci aktifitasaktifitas tersebut adalah sebagai berikut:

\begin{tabular}{|c|c|}
\hline PTij & $=$ Pola tanam ke-i pada tipologi ke-j (Ha) \\
\hline UTnk & $=$ Usaha ternak $(\mathrm{Rp} / \mathrm{th})$ \\
\hline INF & $=$ Pendapatan dari non farm $(\mathrm{Rp} / \mathrm{th})$ \\
\hline BBnh & $=$ Beli benih $(\mathrm{Kg})$ \\
\hline STK & $=$ Sewa tenaga kerja $(\mathrm{HOK})$ \\
\hline $\mathrm{BPO}$ & $=$ Beli pupuk organik $(\mathrm{kg})$ \\
\hline Burea & = Beli pupuk urea $(\mathrm{kg})$ \\
\hline BSP & = Beli pupuk SP36 (kg) \\
\hline $\mathrm{BKCl}$ & $=$ Beli pupuk $\mathrm{KCl}(\mathrm{kg})$ \\
\hline Bherb & $=$ Beli herbisida (liter) \\
\hline BPest & $=$ Beli pestisida $($ Liter) \\
\hline E-FCushtn & $=$ Pengeluaran biaya tetap usahatani $(\mathrm{Rp} / \mathrm{th})$ \\
\hline E-pgn & $=$ Pengeluaran pangan $(\mathrm{Rp} / \mathrm{th})$ \\
\hline E-non pgn & $=$ Pengeluaran non pangan $(\mathrm{Rp} / \mathrm{th})$ \\
\hline J-pd & $=$ Jual padi $(\mathrm{kg})$ \\
\hline J-klp & $=$ Jual kelapa Butir \\
\hline M-PKPpd & $=$ Memenuhi PKP padi-padian(kkal) \\
\hline M-PKPumb & $=$ Memenuhi PKP umbi-umbian (kkal) \\
\hline M-PKPhwn & $=$ Memenuhi PKP pangan hewani (kkal) \\
\hline $\mathrm{M}-\mathrm{PKPkc}$ & $=$ Memenuhi PKP kacang-kacangan (kkal) \\
\hline M-PKPml & $=$ Memenuhi PKP minyak dan lemak (kkal) \\
\hline M-PKPbm & $=$ Memenuhi PKP biji berminyak (kkal) \\
\hline M-PKPbs & $=$ Memenuhi PKP buah dan sayur (kkal) \\
\hline Pgl & $=$ Memenuhi PKP gula \\
\hline M-PKPlain & $=$ Memenuhi PKP pangan lainnya (kkal) \\
\hline
\end{tabular}

Analisis di lakukan untuk masing-masing tipologi dan tipe luapan lahan selama satu tahun. Kendala dan persayaratan, hubungan atau relasi dengan sisi kanan kendala (right hand side) serta rincian kendala dapat dilihat pada tabel berikut:

\begin{tabular}{|c|c|c|c|}
\hline Z & $=$ Fungsi tujuan & $=$ & Rp000 \\
\hline LSj & $=$ Lahan sawah di tipologi ke-j & $\leq$ & На \\
\hline Lkbnj & $=$ Lahan kebun di tipologi ke-j & $\leq$ & $\mathrm{Ha}$ \\
\hline SU:Ternak & = Skal usaha ternak & $\leq$ & ekor/KK \\
\hline I-NF & = Pendapatan non farm & $\leq$ & $\mathrm{Rp} /$ th \\
\hline
\end{tabular}




$\begin{array}{llll}\text { Bnh Pd } & =\text { Stok benih padi } & \leq & \mathrm{kg} \\ \text { TDK } & =\text { Stok tenaga kerja dalam keluarga } & \leq & \mathrm{kg} \\ \mathrm{TLK} & =\text { Stok enaga kerja luar keluarga } & \leq & \mathrm{kg} \\ \mathrm{N} & =\text { Stok Pupuk urea } & \leq & \mathrm{kg} \\ \mathrm{P} & =\text { Stok Pupuk SP36 } & \leq & \mathrm{kg} \\ \mathrm{K} & =\text { Stok Pupuk KCl } & \leq & \mathrm{kg} \\ \mathrm{NPK} & =\text { Stok Pupuk NPK } & \leq & \mathrm{kg} \\ \mathrm{O} & =\text { Stok Pupuk organik } & \leq & \mathrm{kg} \\ \text { Herb } & =\text { Stok Herbisida } & \leq & \mathrm{lt} \\ \text { Pest } & =\text { Stok Pestisida } & \leq & \mathrm{Rp} \\ \text { FC ushtn } & =\text { Stok biaya tetap usahatani } & \leq & \mathrm{Rp} \\ \text { A-non pgn } & =\text { Anggaran konsumsi non pangan } & = & 000 \mathrm{kkal} \\ \text { P-Padi } & =\text { Produksi padi } & = & 000 \mathrm{kkal} \\ \text { P-Klp } & =\text { Produksi kelapa } & = & 000 \mathrm{kkal} \\ \text { PKPpd } & =\text { Syarat PKP padi-padian } & = & 000 \mathrm{kkal} \\ \text { PKPumb } & =\text { Syarat PKP umbi-umbian } & = & 000 \mathrm{kkal} \\ \text { PKPhwn } & =\text { Syarat PKP pangan hewani } & = & 000 \mathrm{kkal} \\ \text { PKPkc } & =\text { Syarat PKP kacang-kacangan } & = & 000 \mathrm{kkal} \\ \text { PKPml } & =\text { Syarat PKP minyak dan lemak } & = & 000 \mathrm{kkal} \\ \text { PKPbm } & =\text { Syarat PKP biji berminyak } & = & 000 \mathrm{kkal} \\ \text { PKPbs } & =\text { Syarat PKP buah dan sayur } & = & 000 \mathrm{kkal} \\ \text { PKPgl } & =\text { Syarat PKP gula } & = & 000 \mathrm{kkal} \\ \text { PKPlain } & =\text { Syarat PKP pangan lainnya } & \end{array}$

Ketahanan pangan rumah tangga tani dalam model linear programing ini tercapai apabila pola konsumsi pangan rumah tangga sesuai dengan Pola Pangan Harapan (PPH) Nasional sebesar $2.000 \mathrm{kkal} / \mathrm{kapita} / \mathrm{hari}$, dengan diversifikasi konsumsi pangan (dalam kkal/kapita/hari) untuk .padi-padian 1000, umbi-umbian 120, pangan hewani 240, kacang-kacangan 100, minyak dan lemak 200, biji berminyak 60, buah dan sayur 120, gula 100, dan lainya 60 (Garjito dan Rauf, 2009) .

\section{Simulasi Dampak Perubahan Harga Input Dan Output}

Setelah solusi optimal primal dan dual dicapai, maka dilakukan analisis sensitivitas dengan tujuan untuk mengetahui perubahan solusi optimal jika terjadi perubahan variabel-variabel penelitian yang sensitif. Makna sensitif disini adalah dengan relatif sedikit perubahan (misal harga input/harga output) maka solusi optimal akan berubah. Dalam penelitian ini, analisis sensitivitas dilakukan untuk menganalisis dampak perubahan harga input dan harga output terhadap pendapatan dan ketahanan pangan rumah tangga tani 


\section{HASIL DAN PEMBAHASAAN}

\section{Solusi Optimal Alokasi Sumberdaya Pertanian dan Ketahanan Pangan Rumah Tangga Tani di Lahan Pasang Surut}

Usahatani yang dilakukan oleh rumah tangga tani di berbagai tipologi lahan pasang surut di Kabupaten Kubu Raya mengikuti pola tanam yang beragam (Tabel 1). Pola tanam-pola tanam tersebut belum tentu merupakan kombinasi pola tanam yang optimal. Untuk mengetahui kombinasi pola tanam yang optimal harus dilakukan analisis optimasi menggunakan linier programming.

Tabel 1. Pola tanam aktual dan optimal pada berbagai tipologi dan tipe luapan di lahan pasang surut Kabupaten Kubu Raya

\begin{tabular}{|c|c|c|c|c|c|}
\hline \multirow{2}{*}{$\begin{array}{l}\mathrm{N} \\
\mathrm{o}\end{array}$} & \multirow{2}{*}{$\begin{array}{l}\text { Tipologi dan Tipe } \\
\text { Luapan Lahan }\end{array}$} & \multirow{2}{*}{$\begin{array}{l}\text { Tipe } \\
\text { Lahan }\end{array}$} & \multirow{2}{*}{$\begin{array}{c}\text { Luas } \\
\text { (ha/KK } \\
\text { ) }\end{array}$} & \multicolumn{2}{|c|}{ Pola Tanam } \\
\hline & & & & Aktual & Optimal \\
\hline 1 & SMA/A & sawah & 1.75 & $\begin{array}{l}\text { padi-padi } \\
\text { Padi-bera }\end{array}$ & padi-padi \\
\hline \multirow[t]{2}{*}{2} & \multirow{2}{*}{$\mathrm{SMP} / \mathrm{A}$} & sawah & 0.78 & $\begin{array}{l}\text { padi-padi } \\
\text { Padi-bera }\end{array}$ & padi-padi \\
\hline & & kebun & 0.86 & kelapa & kelapa \\
\hline \multirow{2}{*}{3} & \multirow{2}{*}{$\mathrm{SMP} / \mathrm{B}$} & sawah & 0.42 & $\begin{array}{l}\text { padi-padi } \\
\text { jagung-jagung }\end{array}$ & jagung-jagung \\
\hline & & kebun & 1.68 & $\begin{array}{l}\text { langsat+durian+kela } \\
\text { pa }\end{array}$ & $\begin{array}{l}\text { langsat+durian+kela } \\
\text { pa }\end{array}$ \\
\hline \multirow[t]{2}{*}{4} & \multirow[t]{2}{*}{$\mathrm{SMP} / \mathrm{C}$} & sawah & 0.99 & $\begin{array}{l}\text { padi-padi } \\
\text { Padi-bera }\end{array}$ & padi-padi \\
\hline & & kebun & 0.60 & kelapa & kelapa \\
\hline \multirow[t]{2}{*}{5} & \multirow[t]{2}{*}{ Bergambut/B } & sawah & 1.20 & $\begin{array}{l}\text { padi-padi } \\
\text { Padi-bera }\end{array}$ & padi-padi \\
\hline & & kebun & 1.50 & kelapa & kelapa \\
\hline \multirow[t]{2}{*}{6} & \multirow[t]{2}{*}{ Bergambut/C } & sawah & 0.98 & $\begin{array}{l}\text { padi-padi } \\
\text { Padi-bera }\end{array}$ & padi-padi \\
\hline & & kebun & 0.28 & kelapa & kelapa \\
\hline 7 & Gambut Sedang/B & sawah & 1.44 & $\begin{array}{l}\text { padi-padi } \\
\text { Padi-bera } \\
\text { jagung-jagung }\end{array}$ & padi-padi \\
\hline 8 & $\begin{array}{l}\text { Gambut } \\
\text { dangkal/D }\end{array}$ & $\begin{array}{l}\text { sawah } \\
\text { kebun }\end{array}$ & $\begin{array}{l}0.42 \\
0.83\end{array}$ & $\begin{array}{l}\text { Padi-bera } \\
\text { karet }\end{array}$ & $\begin{array}{l}\text { padi-padi } \\
\text { karet }\end{array}$ \\
\hline
\end{tabular}

Sumber: Analisis data primer, 2010

Di Kabupaten Kubu Raya terdapat 8 tipe lahan berdasarkan kombinasi tipologi dan tipe luapan lahan, yaitu sulfat masam aktual A, sulfat masam potensial A, sulfat masam potensial B, sulfat masam potensial $C$, bergambut $B$, 
bergambut $\mathrm{C}$, gambut sedang $\mathrm{B}$, dan gambut dangkal D. Pada masing-masing tipe lahan tersebut terdapat beberapa pola tanam.

Pada tabel 1 dapat dilihat pola-pola tanam aktual dan pola tanam-pola tanam optimal. Pola tanam aktual adalah pola tanam yang diterapkan oleh petani dengan variasi seperti kondisi apa adanya di lapangan sehingga jumlahnya relatif banyak. Sedangkan pola tanam optimal adalah pola tanam terpilih yang menghasilkan kombinasi alokasi sumberdaya yang efisien, artinya setiap unit sumberdaya pertanian yang dihasilkan akan menghasilkan pendapatan yang lebih tinggi dibanding kondisi aktual. Dengan demikian jika usahatani akan optimal hendaknya petani mengikuti pola tanam optimal tersebut, sesuai dengan kondisi tipologi lahan dan tipe luapan yang ada.

Setelah pola tanam optimal diketahui, pembahasan berikutnya adalah alokasi sumberdaya pertanian di tingkat rumah tangga tani. Alokasi sumberdaya aktual adalah alokasi sumberdaya di tingkat rumah tangga tani dengan mengikuti pola tanam aktual, sehingga jumlah alokasi sumberdaya tersebut serperti kondisi aktual di lapangan. Sedangkan alokasi sumberdaya pertanian optimal adalah alokasi sumberdaya yang mengikuti pola tanam optimal. Jika pola tanam optimal akan di terapkan maka harus didukung alokasi sumberdaya pertanian optimal.

Alokasi sumberdaya pertanian optimal akan menghasilkan pendapatan usahatani yang optimal sehingga berdampak langsung terhadap pendapatan rumah tangga tani yang optimal. Secara global penggunaan input optimal kadang lebih banyak dibanding input aktual, atau sebaliknya kadang input optimal lebih sedikit dibanding input aktual. Dengan demikian tolok ukur optimal adalah besarnya kontirbusi setiap unit penggunaan input terhadap pendapatan rumah tangga tani. Nampak jelas bahwa alokasi sumberdaya pertanian secara optimal menghasilkan produksi dan pendapatan yang lebih tinggi dibanding kondisi aktual. Secara lebih rinci solusi optimal alokasi sumberdaya pertanian dapat dilihat pada Tabel 2.

Berdasarkan Tabel 2 terlihat bahwa input optimal sebagian besar dialokasikan dalam jumlah yang lebih besar dibanding input aktual oleh setiap rumah tangga tani, kecuali pupuk organik dan benih padi. Namun tolok ukur optimal bukan banyak sedikitnya input tersebut dialokasikan dalam usahatani oleh setiap rumah tangga, melainkan kontribusi setiap unit input terhadap pendapatan rumah tangga tani. Untuk menunjukkan bahwa input optimal lebih efisien dalam memberi kontribusi terhadap pendapatan rumah tangga maka dilakukan perhitungan rasio atau nisbah antara pendapatan rumah tangga tani dengan input yang dialokasikan. Hal ini dapat dilihat pada Tabel 3.

Dari Tabel 3 terlihat bahwa sebagian besar input yang dialokasikan secara optimal akan memberikan kontribusi terhadap pendapatan lebih besar, kecuali tenaga kerja dalam keluarga dan pupuk NPK. Tenaga kerja dalam keluarga merupakan bagian dari pendapatan rumah tangga tani karena secara tunai tenaga kerja bukan merupakan biaya. Sedangkan pupuk NPK dialokasikan pada tanaman perkebuanan yang jumlahnya tidak terlalu banyak (belum sesuai dosis rekomendasi). 
Tabel 2. Solusi optimal alokasi sumberdaya pertanian dan pola konsumsi pangan rumah tangga di lahan pasang surut Kabupaten Kubu Raya

\begin{tabular}{|c|c|c|c|c|c|}
\hline \multirow[b]{2}{*}{ No. } & \multirow[b]{2}{*}{ Uraian } & \multirow[b]{2}{*}{ Satuan } & \multirow[b]{2}{*}{ Aktual } & \multicolumn{2}{|c|}{ Optimal*) $^{*}$} \\
\hline & & & & PKP Aktual & $\begin{array}{c}\text { PKP ideal/ } \\
\text { PPH } \\
\text { Nasional }\end{array}$ \\
\hline I. & Sumberdaya & & & & \\
\hline 1 & Tng dalam keluarga & $\mathrm{HOK} / \mathrm{KK} /$ th & 61.98 & 166.74 & 166.74 \\
\hline 2 & Tng luar keluarga & $\mathrm{HOK} / \mathrm{KK} /$ th & 113.47 & 132.74 & 132.74 \\
\hline 3 & Benih Padi & $\mathrm{kg} / \mathrm{KK} / \mathrm{th}$ & 103.35 & 70.54 & 70.54 \\
\hline 3 & Urea & $\mathrm{kg} / \mathrm{KK} / \mathrm{th}$ & 176.33 & 189.28 & 189.28 \\
\hline 4 & SP36 & $\mathrm{kg} / \mathrm{KK} / \mathrm{th}$ & 92.21 & 94.34 & 94.34 \\
\hline 5 & KCL & $\mathrm{kg} / \mathrm{KK} / \mathrm{th}$ & 50.84 & 56.35 & 56.35 \\
\hline 6 & NPK & $\mathrm{kg} / \mathrm{KK} / \mathrm{th}$ & 34.23 & 75.66 & 75.66 \\
\hline 7 & Pupuk organik & $\mathrm{kg} / \mathrm{KK} / \mathrm{th}$ & 184.41 & 65.99 & 65.99 \\
\hline 8 & Herbisida & $\mathrm{lt} / \mathrm{KK} / \mathrm{th}$ & 7.29 & 8.62 & 8.62 \\
\hline 9 & Pestisida & $\mathrm{lt} / \mathrm{KK} / \mathrm{th}$ & 2.07 & 2.29 & 2.29 \\
\hline II. & Produksi & & & & \\
\hline 1 & Padi & $\mathrm{kg} / \mathrm{KK} / \mathrm{th}$ & $4,032.48$ & $4,839.69$ & $4,839.69$ \\
\hline 2 & Jagung & $\mathrm{kg} / \mathrm{KK} / \mathrm{th}$ & 888.64 & 355.16 & 355.16 \\
\hline 3 & Kelapa & $\mathrm{kg} / \mathrm{KK} / \mathrm{th}$ & $3,693.81$ & $5,063.49$ & $5,063.49$ \\
\hline 4 & Karet & $\mathrm{kg} / \mathrm{KK} / \mathrm{th}$ & 59.43 & 84.66 & 84.66 \\
\hline 5 & Buah-buahan*) & $\mathrm{Rp} / \mathrm{KK} / \mathrm{th}$ & $3,063,181.80$ & $3,063,181.80$ & $3,063,181.80$ \\
\hline 6 & Ternak*) & $\mathrm{Rp} / \mathrm{KK} / \mathrm{th}$ & $1,370,030.00$ & $1,370,030.00$ & $1,370,030.00$ \\
\hline III. & Ketahanan pangan $\left.{ }^{* *}\right)$ & & & & \\
\hline 1 & PKP padi-padian & kkal/kap./hr & $1,156.45$ & $1,156.45$ & 1000.00 \\
\hline 2 & PKP umbi-umbian & kkal/kap./hr & 53.50 & 53.50 & 120.00 \\
\hline 3 & PKP pangan hewani & kkal/kap./hr & 157.92 & 157.92 & 240.00 \\
\hline 4 & PKP kacang-kacangan & kkal/kap./hr & 81.30 & 81.30 & 100.00 \\
\hline 5 & PKP minyak dan lemak & kkal/kap./hr & 29.26 & 29.26 & 200.00 \\
\hline 6 & PKP buah/biji berminyak & kkal/kap./hr & 24.13 & 24.13 & 60.00 \\
\hline 7 & PKP buah dan sayur & kkal/kap./hr & 68.81 & 68.81 & 120.00 \\
\hline 8 & PKP gula & kkal/kap./hr & 134.37 & 134.37 & 100.00 \\
\hline 9 & PKP lainnya & kkal/kap./hr & 65.41 & 65.41 & 60.00 \\
\hline & Total energi & kkal/kap./hr & 1771.14 & 1771.14 & 2000.00 \\
\hline IV. & Pendapatan RT & $\mathrm{Rp} / \mathrm{KK} / \mathrm{th}$ & $2,200,000.00$ & $3,883,234.87$ & $1,285,839.37$ \\
\hline
\end{tabular}

Sumber: Analisis data primer, 2010

*) tidak ditampilkan dalam bentuk fisik karena produk campuran **) $1 \mathrm{KK}=3.9$ orang anggota keluarga 
Tabel 3. Nisbah antara pendapatan dengan unit input yang dialokasikan oleh rumah tangga tani di lahan pasang surut Kabupaen Kubu raya

\begin{tabular}{lrrr}
\hline \multirow{2}{*}{ Jenis Input } & \multirow{2}{*}{ Satuan } & \multicolumn{2}{c}{ Rasio pendapatan dan unit input } \\
\cline { 3 - 4 } & & Kondisi Aktual & Kondisi Optimal \\
\hline Tng kerja dalam keluarga & $\mathrm{Rp} / \mathrm{HOK}$ & $35,494.71$ & $23,289.34$ \\
Tng kerja luar keluarga & $\mathrm{Rp} / \mathrm{HOK}$ & $19,387.68$ & $29,255.27$ \\
Benih Padi & $\mathrm{Rp} / \mathrm{kg}$ & $21,286.82$ & $55,052.06$ \\
Urea & $\mathrm{Rp} / \mathrm{kg}$ & $12,476.66$ & $20,516.09$ \\
SP36 & $\mathrm{Rp} / \mathrm{kg}$ & $23,859.40$ & $41,161.58$ \\
KCL & $\mathrm{Rp} / \mathrm{kg}$ & $43,275.07$ & $68,909.72$ \\
NPK & $\mathrm{Rp} / \mathrm{kg}$ & $64,268.09$ & $51,323.96$ \\
Pupuk organik & $\mathrm{Rp} / \mathrm{kg}$ & $11,929.70$ & $58,850.27$ \\
Herbisida & $\mathrm{Rp} / \mathrm{liter}$ & $301,728.10$ & $450,689.31$ \\
Pestisida & $\mathrm{Rp} / \mathrm{liter}$ & $1,065,091.68$ & $1,699,102.42$ \\
\hline
\end{tabular}

Sumber: Analisis data primer, 2010

Pada solusi optimal produksi beberapa komoditas yang diusahakan hampir semua lebih besar dibanding produksi aktual, kecuali jagung. Komoditas jagung dibeberapa tipologi kurang bersaing (menurut model LP) sehingga tidak muncul disemua lokasi yang ada jagungnya. Sedangkan secara aktual jagung diusahakan dibeberapa tempat, dengan demikian produksi aktual lebih besar dibanding produksi optimal. Akan tetapi secara umum semua komoditas menunjukkan produksi yang lebih tinggi dibanding produksi aktual.

Pola konsumsi pangan (PKP) harian masyarakat sering kurang memenuhi standar kecukukupan gizi yang diharapkan atau pola pangan harapan (PPH). Pola konsumsi pangan (PKP) merupakan susunan beragam pangan yang dikonsumsi oleh masyarakat secara aktual. Sedangkan pola pangan harapan $(\mathrm{PPH})$ adalah susunan beragam pangan yang didasarkan pada proporsi keseimbangan energi dari kelompok pangan utama dengan mempertimbangkan ketersediaan pangan, daya terima masyarakat, daya beli, budaya, dan agama.

Susunan PPH nasional hasil Widya Karya Nasional Pangan dan Gizi ke-9 (WNPG IX) tahun 2008 mengelompokkan bahan pangan menjadi 9 kelompok dan total konsumsi energi sebesar $2.000 \mathrm{kkal} / \mathrm{kapita} / \mathrm{hari}$. Selanjutnya tingkat konsumsi energi masyarakat dibagi menjadi tiga ketegori, yaitu (1) sangat rawan pangan, apabila tingkat konsumsi energi kurang dari 70\% AKG atau 1.400 $\mathrm{kkal} / \mathrm{kapita} / \mathrm{hari}$, (2) rawan pangan, apabila tingkat konsumsi energi antara 7089\% AKG atau 1.400-1800 kkal/kapita/hari, dan (3) tahan pangan, apabila tingkat konsumsi energi lebih dari $90 \%$ AKG atau di atas $1.800 \mathrm{kkal} / \mathrm{kapita} / \mathrm{hari}$ (Garjito dan Rauf, 2009).

Dari hasil survey diketahui bahwa konsumsi energi masyarakat tani di lahan pasang surut kabupaten Kubu Raya baru mencapai 1.771,14 kkal/kapita/hari. Dengan demikian konsumsi energi masyarakat tani di lahan pasang surut Kabupaten Kubu Raya masuk dalam kategori rawan pangan. 
Untuk dapat meningkat ke kategori tahan pangan maka perlu ada peningkatan konsumsi energi minimal 228,86 kkal/kapita/hari atau 12,92\%.

Diversifikasi konsumsi pangan masyarakat tani di lahan pasang surut Kabupaten Kubu Raya sudah menunjukkan pola yang cukup baik. Beberapa kelompok pangan dikonsumsi dalam jumlah yang lebih besar dibanding PPH nasional seperti padi-padian, gula, dan pangan lainnya. Sedangkan kelompok umbi-umbian, pangan hewani, kacang-kacangan, minyak dan lemak, buah/biji berminyak, buah dan sayur dikonsumsi lebih rendah dari PPH Nasional. Instansi terkait perlu mencermati pola konsumsi masyarakat tersebut untuk ditingkatkan sesuai PPH Nasional.

Peluang untuk meningkatkan pola konsumsi pangan (PKP) harian menuju PPH Nasional sangat memungkinkan karena didukung oleh pendapatan rumah tangga tani yang cukup. Hal ini dapat dilihat dari hasil optimasi, yang menunjukkan bahwa dengan syarat $\mathrm{PPH}$ nasional pendapatan rumah tangga tani masih ada kelebihan $\mathrm{Rp} 1.285 .839,37 / \mathrm{KK} /$ tahun. Jika syarat PPH nasional dihilangkan, dan rumah tangga tani mengkonsumsi energi sesuai kondisi aktual diperoleh pendapatan rumah tangga hasil optimasi sebesar Rp 3.883.234,87/KK/tahun. Sedangkan pendatan rumah tangga tani aktual adalah sebesar Rp 2.200.000,00/KK/tahun. Dengan demikian membuktikan bahwa optimasi alokasi sumberdaya pertanian dan pola tanam akan mampu meningkatkan pendapatan rumah tangga tani dari Rp 2.200.000,00/KK/tahun menjadi 3.883.234,87/KK/tahun atau meningkat sebesar 76,51\%. Sementara jika peningkatan pendapatan rumah tangga tani tersebut digunakan untuk keperluan konsumsi energi sesuai $\mathrm{PPH}$ Nasional maka pendapatan rumah tangga tani masih ada saving 1.285.839,37/KK/tahun.

\section{Analisis Sensitifitas Perubahan Harga Input Dan Harga Output}

Analisis sensitifitas merupakan bagian dari analisis optimasi secara keseluruhan. Analisis sensitifitas dilakukan untuk mengetahui limit/batas minimum dan limit/batas maksimum dari perubahan harga input dan harga output yang tidak merubah solusi optimal. Perubahan harga secara individual yang masih berada pada range batas minimum dan batas maksimum hanya akan merubah nilai tujuan, dalam hal ini pendapatan rumah tangga tani. Sedangkan solusi pilihan aktifitasnya tidak berubah. Perubahan harga secara individual yang melebihi batas minimum dan batas maksimum akan merubah solusi optimal atau merubah pilihan-pilihan aktifitas. Namun jika perubahan harga tersebut secara bersama-sama, bisa merubah dan bisa tidak tergantung besarnya perubahan harga tersebut.

Jika selisih harga input atau harga output dengan batas minimum dan harga maksimum kecil maka bisa dikatakan bahwa harga input atau harga output tersebut sensitif terhadap perubahan harga, sebaliknya jika selisih harga input atau harga output dengan batas minimum dan harga maksimum besar maka bisa dikatakan bahwa harga input atau harga output tersebut tidak sensitif terhadap perubahan harga. 
Untuk mengetahui secara lebih rinci tentang analisis sensitifitas haga input dan harga output dapat dilihat pada Tabel 4. Berdasarkan tabel tersebut terlihat bahwa harga padi dan harga jagung merupakan harga-harga yang paling sensitif terhadap kenaikan maupun penurunan harga. Jika harga padi naik lebih dari 5\% atau harga jagung naik lebih dari 50\% secara individual (cateris paribus) maka solusi optimal akan berubah. Demikian juga jika harga padi turun lebih dari $34 \%$ atau harga jagung turun lebih dari $9 \%$ secara individual (cateris paribus) maka solusi optimal akan berubah. Sementara harga-harga yang lain tidak sensitif karena batas minimum dan batas maksimumnya cukup besar, sehingga untuk dapat merubah solusi optimal perlu ada perubahan harga yang cukup besar.

Tabel 4. Analisis Sensitifitas Perubahan Harga Input Dangan Harga Output Di Lahan Pasang Surut Kabupaten Kubu Raya

\begin{tabular}{|c|c|c|c|c|c|c|c|}
\hline \multirow{2}{*}{ No. } & \multirow{2}{*}{ Variabel } & \multirow{2}{*}{ Satuan } & \multirow{2}{*}{$\begin{array}{l}\text { Unit } \\
\text { Cost }\end{array}$} & \multicolumn{2}{|c|}{ Batas Minimum } & \multicolumn{2}{|c|}{ Batas Maksimum } \\
\hline & & & & Nilai & $\%$ turun & Nilai & $\%$ naik \\
\hline I. & Harga input & & & & & & \\
\hline 1 & benih padi & $\mathrm{Rp} / \mathrm{kg}$ & $3,694.00$ & 0.00 & $-100 \%$ & $104,205.70$ & $2721 \%$ \\
\hline 2 & tenaga kerja & $\mathrm{Rp} / \mathrm{HOK}$ & $38,821.00$ & $2,362.24$ & $-94 \%$ & $77,479.34$ & $100 \%$ \\
\hline 3 & Urea & $\mathrm{Rp} / \mathrm{kg}$ & $1,562.00$ & 0.00 & $-100 \%$ & $36,221.20$ & $2219 \%$ \\
\hline 4 & SP 36 & $\mathrm{Rp} / \mathrm{kg}$ & $2,351.00$ & 0.00 & $-100 \%$ & $107,087.00$ & $4455 \%$ \\
\hline 5 & $\mathrm{KCl}$ & $\mathrm{Rp} / \mathrm{kg}$ & $3,330.00$ & 0.00 & $-100 \%$ & $140,784.60$ & $4128 \%$ \\
\hline 6 & NPK & $\mathrm{Rp} / \mathrm{kg}$ & $3,645.00$ & 0.00 & $-100 \%$ & M & M \\
\hline 7 & pupuk Organik & $\mathrm{Rp} / \mathrm{kg}$ & 635.00 & 0.00 & $-100 \%$ & $14,277.81$ & $2148 \%$ \\
\hline 8 & herbisida & Rp/liter & $45,644.00$ & 0.00 & $-100 \%$ & $593,889.50$ & $1201 \%$ \\
\hline 9 & pestisida & Rp/liter & $70,027.00$ & 0.00 & $-100 \%$ & $3,050,199.00$ & $4256 \%$ \\
\hline II. & Harga Output & & & & & & \\
\hline 1 & padi & $\mathrm{Rp} / \mathrm{kg}$ & $3,215.00$ & $2,123.57$ & $-34 \%$ & $3,486.20$ & $8 \%$ \\
\hline 2 & jagung & $\mathrm{Rp} / \mathrm{kg}$ & $2,326.00$ & $2,115.82$ & $-9 \%$ & $3,498.94$ & $50 \%$ \\
\hline 3 & kelapa & Rp/butir & 935.00 & 0.00 & $-100 \%$ & M & $\mathrm{M}$ \\
\hline 4 & karet & $\mathrm{Rp} / \mathrm{kg}$ & $6,800.00$ & 0.00 & $-100 \%$ & M & M \\
\hline
\end{tabular}

Sumber: analisis data primer, 2010

Jika kenaikan atau penurunan harga secara bersama-sama akan terjadi dua kemungkinan, yaitu (1) terjadi perubahan nilai tujuan sedangkan solusi optimal tetap, (2) terjadi perubahan nilai tujuan dan sekaligus perubahan solusi optimal. Selanjutnya, jika mengamati fluktuasi harga input dan harga output di pasar, bisa disimpulkan bahwa fluktuasi harga input relatif kecil dan cenderung meningkat. Sedangkan fluktuasi harga output relatif besar dan bisa naik-turun.

Untuk mengetahui dampak perubahan harga input dan harga output terhadap solusi optimal dan pendapatan rumah tangga, akan dilakukan simulasi dengan 2 skenario, yaitu (1) kenaikan harga input dan harga output 10\% secara 
bersama-sama (Tabel 5), dan (2) penurunan harga output 10\% dan harga input tetap (Tabel 6). Untuk skenario 2 hanya harga output yang turun sedangkan harga input tetap, karena dalam kenyataanya peluang harga turun yang paling besar adalah harga output sedangkan harga input cenderung tetap atau naik (hampir tidak pernah turun).

Tabel 5. Simulasi Kenaikan Harga Input Dan Harga Output Sebesar 10\% Pada Solusi Optimal Di Lahan Pasang Surut Kabupaten Kubu Raya.

\begin{tabular}{llrrr}
\hline & & & \multicolumn{2}{c}{ Optimal ${ }^{*}$ ) } \\
\cline { 5 - 6 } No. Uraian & Satuan & Aktual & PKP Aktual & \multicolumn{1}{c}{ PPH } \\
Nasional
\end{tabular}

Sumber: Analisis data primer, 2010. Ket: $\left.{ }^{*}\right) 1 \mathrm{KK}=3.9$ orang anggota keluarga

Hasil simulasi kenaikan harga input dan harga output $10 \%$ ternyata tidak merubah solusi optimal, baik pola tanam, jumlah input, maupun jumlah output. Perubahan harga input dan output $10 \%$ hanya merubah fungsi tujuan, yaitu pendapatan rumah tangga. Pendapatan rumah tangga naik $37,87 \%$ untuk solusi optimal tanpa syarat PPH nasional, dan pendapatan naik $114.37 \%$ untuk solusi optimal dengan syarat PPH Nasional, namun secara nominal kenaikan lebih besar untuk solusi optimal tanpa syarat PPH nasional. Dengan pendapatan yang meningkat tersebut maka peluang untuk meningkatkan konsumsi energi ke PPH Nasional akan meningkat. 
Seperti halnya simulasi 1, penurunan harga output $10 \%$ dan harga input tetap, ternyata tidak merubah solusi optimal, baik pola tanam, jumlah input, maupun jumlah output. Perubahan harga output $10 \%$ dan harga input tetap hanya merubah fungsi tujuan, yaitu pendapatan rumah tangga. Pendapatan rumah tangga turun $152.15 \%$ untuk solusi optimal PKP aktual (konsumsi energi sesuai kondisi aktual), dan pendapatan turun $459,49 \%$ untuk solusi optimal dengan syarat PPH Nasional, namun secara nominal penurunan lebih besar untuk solusi optimal dengan syarat PPH nasional.

Tabel 6. Simulasi penurunan harga output sebesar 10\% dan harga input tetap pada solusi optimal di lahan pasang surut Kabupaten Kubu Raya.

\begin{tabular}{|c|c|c|c|c|c|}
\hline \multirow{2}{*}{ No. } & \multirow{2}{*}{ Uraian } & \multirow{2}{*}{ Satuan } & \multirow{2}{*}{ Aktual } & \multicolumn{2}{|c|}{ Optimal $\left.^{*}\right)$} \\
\hline & & & & PKP Aktual & PPH Nasional \\
\hline I. & Sumberdaya & & & & \\
\hline 1 & TK dalam keluarga & $\mathrm{HOK} / \mathrm{KK} /$ th & 61.98 & 166.74 & 166.74 \\
\hline 2 & TK luar keluarga & $\mathrm{HOK} / \mathrm{KK} /$ th & 113.47 & 132.74 & 132.74 \\
\hline 3 & Benih Padi & $\mathrm{kg} / \mathrm{KK} / \mathrm{th}$ & 103.35 & 70.54 & 70.54 \\
\hline 3 & Urea & $\mathrm{kg} / \mathrm{KK} / \mathrm{th}$ & 176.33 & 189.28 & 189.28 \\
\hline 4 & SP36 & $\mathrm{kg} / \mathrm{KK} / \mathrm{th}$ & 92.21 & 94.34 & 94.34 \\
\hline 5 & KCL & $\mathrm{kg} / \mathrm{Kl}$ & 5 & 56.35 & 56.35 \\
\hline 6 & NPK & $\mathrm{kg} / \mathrm{KK} / \mathrm{th}$ & 23 & 75.66 & 75.66 \\
\hline 7 & Pupuk orga & $\mathrm{kg} / \mathrm{K}$ & 184 & 65.99 & 65.99 \\
\hline 8 & Herbis & $\mathrm{lt} / \mathrm{Kl}$ & 7.29 & 8.62 & 8.62 \\
\hline 9 & Pestisida & $\mathrm{lt} / \mathrm{KK} / \mathrm{th}$ & 2.07 & 2.29 & 2.29 \\
\hline II. & Produksi & & & & \\
\hline 1 & Padi & $\mathrm{kg} / \mathrm{KK} / \mathrm{th}$ & $4,032.48$ & $4,839.69$ & $4,839.69$ \\
\hline 2 & Jagung & $\mathrm{kg} / \mathrm{H}$ & 88 & 355.16 & 355.16 \\
\hline 3 & Kelapa & $\mathrm{kg} / \mathrm{l}$ & $3,693.81$ & $5,063.49$ & $5,063.49$ \\
\hline 4 & Karet & $\mathrm{kg} / \mathrm{KK} / \mathrm{th}$ & 59.43 & 84.66 & 84.66 \\
\hline III. & Pendapatan $\mathrm{RT}^{*}$ ) & & & & \\
\hline & $\begin{array}{l}\text { Sebelum } \\
\text { penurunan }\end{array}$ & $\mathrm{Rp} / \mathrm{KK} / \mathrm{th}$ & $2,200,000.00$ & $3,883,234.87$ & $1,285,839.37$ \\
\hline & $\begin{array}{l}\text { Sesudah } \\
\text { penurunan }\end{array}$ & $\mathrm{Rp} / \mathrm{KK} / \mathrm{th}$ & $2,200,000.00$ & $-2,025,051.25$ & $-4,622,446.25$ \\
\hline & $\%$ penurunan & & $0 \%$ & $152.15 \%$ & $459.49 \%$ \\
\hline
\end{tabular}

Sumber: Analisis data primer, 2010. Ket: *) $1 \mathrm{KK}=3.9$ orang anggota keluarga

Penurunan harga output 10\% menyebabkan rumah tangga harus berhutang (pendapatan bertanda negatif) sebesar Rp 2,025,051.25/th untuk mencukupi seluruh kebutuhannya, termasuk jika harus mengkonsumsi energi sesuai kondisi aktual. Jika mengkonsumsi energi sesuai PPH nasional maka rumah tangga tersebut akan berhutang Rp 4,622,446.25/th. Dengan demikian penurunan harga output $10 \%$ akan mengancam tingkat ketahanan pangan rumah tangga. 


\section{SIMPULAN DAN SARAN}

\section{Simpulan}

1. Pola tanam optimal usahatani di lahan pasang surut adalah sebagai berikut: (a) lahan SMA/A, untuk sawah padi-padi, (b) lahan SMP/A untuk sawah padi-padi dan lahan kebun adalah kelapa, (c) lahan SMP/B untuk sawah jagung-jagung dan lahan kebun adalah buah-buahan, (d) lahan SMP/C untuk sawah padi-padi dan untuk lahan kebun kelapa, (e) bergambut/B untuk sawah padi-padi dan untuk lahan kebun kelapa, (f) bergambut/C untuk sawah padi-padi dan untuk lahan kebun kelapa, (g) gambut sedang/B untuk sawah padi-padi, (h) gambut dangkal/D untuk sawah padi-padi dan untuk lahan kebun karet.

2. Alokasi sumberdaya pertanian optimal per rumah tangga tani adalah: tenaga kerja dalam keluarga $166.74 \mathrm{HOK} /$ th, tenaga kerja luar keluarga 132.74 $\mathrm{HOK} / \mathrm{th}$, benih padi $70.54 \mathrm{~kg} / \mathrm{th}$, Urea $189.28 \mathrm{~kg} / \mathrm{th}$, SP36 $94.34 \mathrm{~kg} / \mathrm{th}, \mathrm{KCl}$ $56.35 \mathrm{~kg} / \mathrm{th}$, NPK $75.66 \mathrm{~kg} / \mathrm{th}$, pupuk organik $65.99 \mathrm{~kg} /$ th, herbisida 8.62 lt/th, dan pestisida $2.29 \mathrm{lt} / \mathrm{th}$.

3. Pendapatan aktual rumah tangga adalah $\mathrm{Rp} 2.200 .000,00 / \mathrm{KK} /$ tahun, jika dilakukan optimasi tanpa syarat PPH nasional meningkat menjadi Rp 3.883.234,87/KK/tahun dan jika ada syarat PPH Nasional turun menjadi Rp $1.285 .839,37 / \mathrm{KK} /$ tahun.

4. Harga-harga yang paling sensitif terhadap fluktuasi harga adalah harga padi dan harga jagung. Jika harga padi naik $>5 \%$ atau harga jagung naik $>50 \%$ secara individual (cateris paribus) maka solusi optimal akan berubah. Demikian juga jika harga padi turun $>34 \%$ atau harga jagung turun $>9 \%$ secara individual (cateris paribus) maka solusi optimal akan berubah.

5. Hasil simulasi menunjukkan bahwa kenaikan harga input dan harga output $10 \%$ ternyata tidak merubah solusi optimal. Tetapi berdampak pada kenaikan pendapatan rumah tangga sebesar $37,87 \%$ untuk solusi optimal tanpa syarat PPH nasional, dan $114.37 \%$ untuk solusi optimal dengan syarat PPH Nasional . Sedangkan simulasi penurunan harga output 10\% dan harga input tetap, ternyata tidak merubah solusi optimal, tetapi berdampak pada penurunan pendapatan rumah tangga sebesar $152.15 \%$ untuk solusi optimal PKP aktual dan 459,49\% untuk solusi optimal dengan syarat PPH Nasional.

\section{Saran}

1. Perlu adanya upaya sosialisasi, advokasi, dan dukungan yang memadai dalam rangka penerapan pola tanam optimal sesuai dengan tipologi lahan dan tipe luapan sehingga diperoleh pendapatan usahatani di lahan pasang surut yang maksimal.

2. Konsumsi energi masyarakat tani di lahan pasang surut mencapai $1.771,14$ $\mathrm{kkal} / \mathrm{kapita} / \mathrm{hari}$ atau masuk dalam kategori rawan pangan. Untuk dapat meningkat ke kategori tahan pangan maka perlu ada peningkatan konsumsi energi minimal 228,86 kkal/ kapita/hari atau $12,92 \%$. 


\section{DAFTAR PUSTAKA}

[BPS Propinsi Kalimantan Barat]. 2006. Kalimantan Barat Dalam Angka Tahun 2006. Badan Pusat Statistik Propinsi Kalimantan Barat. Pontianak

Elvindri and Gouranga L. Dasvarma. 1996. Child Malnutrition in Indonesia. Bulletin of Indonesian Ecoomic Studies 32 (1), p. 97-111

Garjito dan Rauf, 2009. Perencanaan Pangan Menuju ketahanan Pangan dan Gizi Serta Kedaulatan Pangan. Pusat Kajian Makanan Tradisional. Universitas Gadjah Mada. Yogyakarta

Heady, Earl O. And Wilfred Candler. 1973. Linier Programming Methods. Seventh Edition. The Iowa State University Press. Ames.

Monteverde, Richard Thomas. 1987. Food Consumption in Indonesia. Unpublished PhD Thesis. Department of Economics. Hardvard University. Cambridge.

Nasir, M. 1988. Metode Penelitian. Ghalia Indonesia. Jakarta.

Pabinru, Muin, dan Hadewi P. Saliem. 1993. Kecukupan dan Ketahanan Pangan. Prisma. p. 33-43.

Pakpahan, A. 2008. Membangun Ketahanan Pangan dengan Replikasi Modalitas Industri Gula, Suara Pembaharuan, 22 Januari 2008.

Pakpahan, Agus. 1993. Perkembangan Kesejahteraan Petani Pangan. Prisma. p. 33-43.

Pambudy, R. 2006. Ketahanan Pangan dalam Sistem dan Usaha Agribisnis: Pemberdayaan Petani dan Organisasi Petani. Prosiding "Revitalisasi Ketahanan Pangan: Membangun Kemandirian Pangan Berbasis Pedesaan" 2006. Pusat Sosial Ekonomi dan Kebijakan Pertanian. Bogor

Pasaribu, Amudi. 1983. Pengantar Statistik. Ghalia Indonesia. Jakarta Timur.

Soetrisno, Noer. 1995. Ketahanan Pangan Dunia: Konsep, Pengukuran, dan Faktor Dominan. Jurnal Pangan 21. p. 27-33

Soetrisno, Noer. 1996. Ketersediaan dan Dsitribusi Pangan dalam Rangka Mendukung Ketahanan Pangan Rumah Tangga. Makalah disampaikan pada Lokakarya Ketahanan Pangan Rumah Tangga. Departemen Pertanian UNICEV. Yogyakarta. 26-30 Mei 1996.

Suhardjo. 1994. Trend of Food Consumption versus Desirable Dietry Pattern. Indonesian Food Journal. p. 55-65.

Supranto, Johanes. 1983. Ekonometrika. Lembaga Penerbit Fakultas Ekonomi Universitas Indonesia. Jakarta 
Suratno dan L. Arsyad. 1988. Ekonomi Mikro. BPFE Universitas Gadjah Mada. Yogyakarta.

Suryana A. 2008. Kebijakan Ketahanan Pangan Nasional. Makalah disampaikan pada Simposium Nasional Ketahanan dan Keamanan Pangan pada Era Otonomi dan Globalisasi, Faperta, IPB, Bogor, 22 November 2005

Teken, I. B. 1965. Penelitian di Bidang Ilmu Ekonomi Pertanian dan Beberapa Metode Pengambilan Contoh. Fakultas Pertanian IPB.

Welirang, F. 2007. Jalan Tengah Sempurna Ketahanan Pangan Indonesia. PT. Indofood Sukses Makmur Bogasari Flour Mills. Jakarta 